\title{
El yin y el yang de los entremeses cervantinos (Miguel de Cervantes, Dos nuevos entremeses, «nunca representados», Dir. Ernesto Arias, Teatro La Abadía, Madrid, diciembre del 2017)
}

\author{
Esther Fernández \\ Rice University \\ ESTADOS UNIDOS \\ ef14@rice.edu
}

[Hipogrifo, (issn: 2328-1308), 6.2, 2018, pp. 841-844]

Recibido: 26-02-2018 / Aceptado: 20-03-2018

DOI: http://dx.doi.org/10.13035/H.2018.06.02.60

En 1996, justo un año después de que el madrileño Teatro de la Abadía abriera sus puertas, José Luis Gómez dirigió Entremeses de Cervantes, un montaje que reunía La cueva de Salamanca, El viejo celoso y El retablo de las maravillas. Este tríptico se convirtió con los años en una de las firmas artísticas de este teatro por una serie de razones que merecen un exhaustivo análisis por separado. Los que tuvimos la suerte de asistir a ese primer montaje de 1996, no olvidaremos el árbol seco que dominaba el centro de la escena. Este, además de servir como eje simbólico en torno al cual se desarrollaba el espectáculo, simbolizaba la energía estival de la vida que brotaba de la tierra. En la puesta en escena dominaba un tono alegre donde una serie de personajes se salían con la suya y se burlaban de las reglas de una sociedad obsesionada con el honor. Tal fue el impacto que dejó este primer montaje en la memoria de los espectadores que casi veinte años más tarde, en el 2015, el mismo Gómez volvió a reponer en el mismo teatro ese primer montaje icónico como conmemoración de su hito escénico.

En el 2017, Ernesto Arias continúa con esta tradicional saga entremesil y la amplía con dos nuevos entremeses, La guarda cuidadosa y El rufián viudo llamado Trampagos, más una adaptación del discurso de Marcela del Quijote que Arias titula, Monólogo de la doncella determinante. Estas tres piezas breves forman un espectáculo independiente pero que a la vez viene también a complementar ese ciclo iniciado por Gómez hace dos décadas. El «árbol de la vida», símbolo central de 
la escenografía del montaje original, se substituye aquí por un pozo que transmite connotaciones muy distintas.

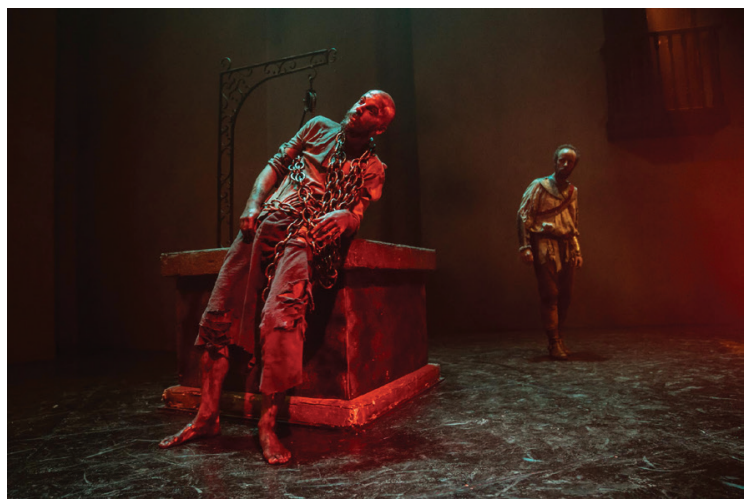

Fig. 1 Escenografía del montaje

Fotógrafo Sergio Parra. Foto cortesía del Teatro de la Abadía

El ambiente veraniego y luminoso de la puesta en escena de Gómez se convierte en la versión de Arias en el mundo de la noche dominado por el hampa y el inframundo rufianesco. No obstante, y aunque de manera muy distinta, el ambiente festivo ocupa también un papel central en esta puesta en escena a través de bailes y de canciones adaptadas de otros textos cervantinos como «Ya que quieres cruel que se publique» (Don Quijote, XIV), «Afuera consejos vanos» (El rufián dichoso), «O le falta al amor conocimiento» (Don Quijote, XXIII).

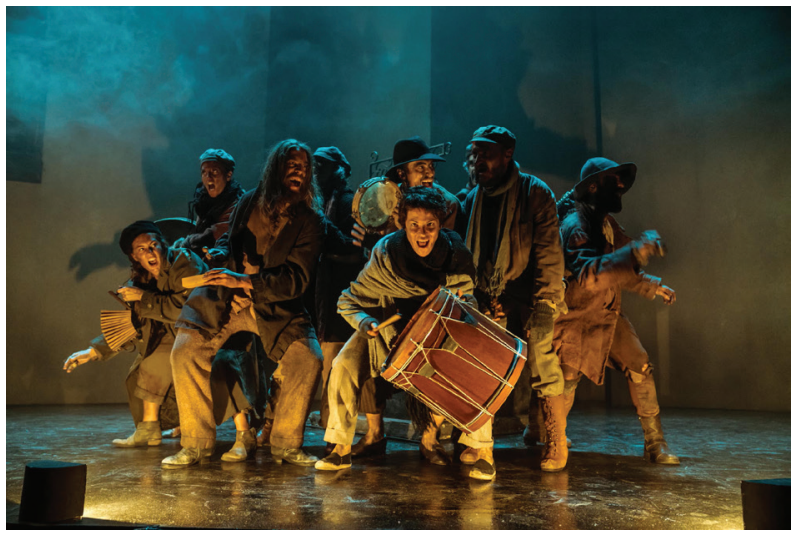

Fig. 2 Coreografía de una de las canciones.

Fotógrafo Sergio Parra. Foto cortesía del Teatro de la Abadía

Los dos entremeses y el Monólogo de la doncella determinante están unidos por el tema de la libre elección, irónicamente junto al papel que el dinero juega en estas elecciones. Mientras que en el caso de La guarda cuidadosa y El rufián viudo, 
la seguridad económica es el motor de las decisiones de Cristinica y Trampagos, respectivamente; la posición social de la doncella determinante (Marcela), le permite huir del matrimonio y decidirse por la independencia sin sujeción alguna. Este mundo, regido por la necesidad de sobrevivir, cada uno a su manera, está simbolizado por el pozo que escupe a sus criaturas hacia una sociedad mucho más descarnada y violenta que el bucolismo que dominaba el montaje de Gómez.

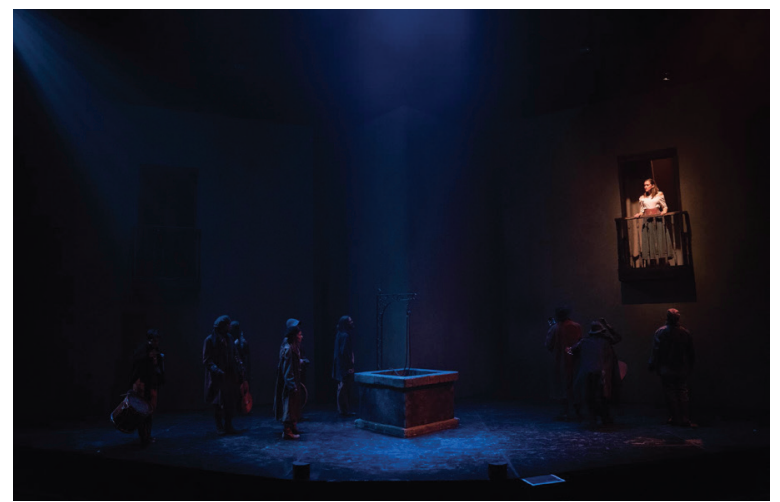

Fig. 3 «Monólogo de la doncella determinante» (Carmen Valverde) Fotógrafo Sergio Parra. Foto cortesía del Teatro de la Abadía

La naturaleza viene aquí a ser remplazada por un ambiente celestinesco más urbano, de callejones oscuros e intrigas, en cierto modo ridículas, pero donde el amor y el deseo tienen un precio. Escarramán sale del pozo con sus cadenas y deambula como alma en pena en silencio por la escena a lo largo de la representación hasta que una vez despojado de sus cadenas parece tomar vida en el desenlace de El rufián viudo y convertirse en una de las figuras más vitales del entremés. El lenguaje de Escarramán es el del cuerpo, el del baile, aumentando así la vitalidad. De hecho la intensidad y eficacia de la coreografía en este montaje le acercan a la danza.

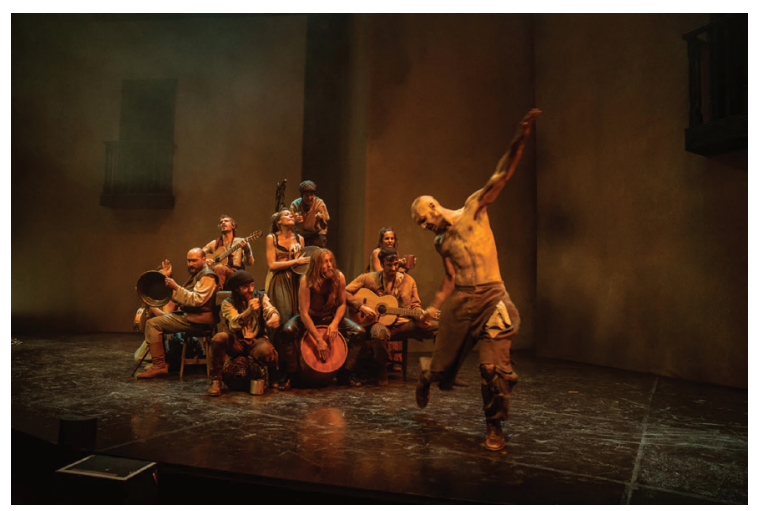

Fig. 4 El baile de Escarramán (José Juan Sevilla) Fotógrafo Sergio Parra. Foto cortesía del Teatro de la Abadía 
La actuación por parte de un elenco de actores afiliados al Teatro de la Abadía es impecable en todos los niveles (gestualidad, voz, movimiento). Paralelamente, la comicidad no cae en lo exagerado en ningún momento. El humor tampoco se trata de manera fácil sino que surge de la esencia del propio entremés. Además del simbolismo del decorado, el cual hemos venido analizando por su papel clave, la caracterización de los actores resalta ese mundo de los márgenes con guiños esperpénticos.

En suma, el montaje de Arias es de un gran valor por llevar a escena dos primicias raramente representadas en un escenario comercial. Si bien La guarda cuidadosa sí se había llevado a las tablas con anterioridad, El rufián viudo y la adaptación del discurso de Marcela al espacio escénico no han tenido, que yo sepa, una trayectoria en las tablas hasta la fecha. No obstante, Dos nuevos entremeses, «nunca representados», también se ha concebido como una continuación o un espectáculo complementario a la versión de los entremeses de Gómez, casi como para cerrar la memoria de un montaje que con el tiempo se ha convertido en icónico. El próximo paso sería montar un doble espectáculo en el que se pudieran ver en un solo pase las versiones de Gómez y de Arias para resaltar el yin y el yang de unos entremeses donde los personajes se aferran por sobrevivir de maneras distintas, dentro de ese universo cervantino multifacético. 